\title{
Pros

\section{NUEVE PREGUNTAS A PABLO MONTOYA. PEREGRINACIONES DEL ARTISTA, EL PENSADOR Y EL PERSONAJE LITERARIO*}

\author{
NINE QUESTIONS TO PABLO MONTOYA. \\ PILGRIMAGES OF THE ARTIST, THE THINKER, \\ AND THE LITERARY CHARACTER
}

Orfa Kelita VANegas

Universidad del Tolima okvanegasv@ut.edu.co

Pablo Montoya es uno de los escritores e intelectuales más notables en el campo de las letras colombianas actuales. Ha publicado un número importante de cuentos, novelas y ensayos de crítica literaria y estética. Su novela Tríptico de la infamia ganó el Rómulo Gallegos 2015, y le mereció otros premios importantes, aparte de la visibilidad y reconocimiento más allá de las fronteras latinoamericanas. He seguido el recorrido de la escritura de Pablo Montoya por más de una década, cuando publicó su libro de cuentos Réquiem por un fantasma. No obstante, es a partir de 2012, con la publicación de Los derrotados, que inicié un estudio más cercano y académico a las apuestas de escritura que sus publicaciones ofrecen. El diálogo estrecho entre lenguaje visual, lenguaje sonoro-musical y lenguaje literario ha sido el núcleo no solo de mis intereses de investigación sino también de otros estudiosos de la narrativa de Montoya, entre ellos Susana Zanetti, Ana María Amar Sánchez, Mónica Marinone, Carolina Sancholuz o Jingting Zhang. En esta ocasión he querido diseñar un encuentro directo con Pablo para conversar sobre aspectos inherentes a su estilo literario, su mirada ética y política del hacer literario y conocer quizás, sobre sus futuros planes de escritura. Comencemos con las nueve preguntas a Pablo Montoya:

Orfa Kelita Vanegas: Dice Borges recordando a Heráclito: "el hombre de ayer no es el hombre de hoy y el de hoy no será el de mañana". Cuando miras hacia atrás tu

\footnotetext{
* Esta entrevista se inscribe en el proyecto de investigación "Tramas emocionales y sociedad percibida en la narrativa colombiana reciente" (2019-2022. CÓD. 30120), adscrito al grupo de investigación Estudios Interdisciplinarios en Literatura, Arte y Cultura (EILAC), de la Universidad del Tolima, Colombia.
} 
devenir escritor, ¿cuáles serían para ti los cambios más decisivos en tu proceso literario y en tu perspectiva sobre el rol del escritor en el panorama social contemporáneo?

Pablo Montoya: Creo que ha habido una relación continua entre mi proceso literario y el rol social que he desempeñado como escritor. En este sentido, ubico cuatro períodos en mi "devenir artístico". El primero se sitúa en Tunja, ciudad donde publiqué mis primeros textos. Es un tiempo, sobre todo, de aprendizaje. Allí están los cuentos musicales de La sinfónica, mis primeros ensayos y poemas en prosa. En Tunja también nació, nítida, la idea de lo que más tarde sería La escuela de música. Durante esos años (1984-1993), leí a autores fundamentales: Dostoievski, Tolstoi, Kafka, Mann, Borges, Carpentier, Rulfo, Cortázar, entre otros. Al lado de este aprendizaje literario, sucede el de la música, el acercamiento a la obra de los grandes compositores, el estudio de la filosofía. Y comencé también a forjar mi proyección social como escritor. Fundé, en compañía de algunos amigos, una revista cultural, fui miembro de un cine club, músico de una orquesta sinfónica y de varios conjuntos de música popular, me vinculé con actividades artísticas y políticas en la UPTC. Recuerdo que cuando la policía asesinó a Tomás Herrera Cantillo, estudiante amigo de esta universidad, escribí un texto de protesta que pegamos en uno de los muros de esta universidad. Conservo ese texto y allí ya se ve con claridad mi posición antimilitarista siguiendo las enseñanzas del viejo Tolstoi. También escribí notas de programa de mano para los conciertos del Festival Internacional de la Cultura. Este primer período culminó con la obtención del Premio Nacional de cuento Germán Vargas, organizado por el periódico El Tiempo, mi obtención de la Licenciatura en Filosofía y Letras de la Universidad a distancia de Santo Tomás de Aquino y mi partida a Francia.

Luego vino el período de París (1993-2002), donde se presentaron el aprendizaje de la lengua francesa y mis estudios de maestría y doctorado en la Sorbona. En esos años comprendí que el viaje y el exilio serían temas fundamentales en mi obra. Asimilé de la mejor manera la literatura francesa, desde Villon hasta Houellebecq. Resultaron esenciales mis lecturas de Montaigne, Baudelaire, Flaubert, Víctor Hugo, Schwob, Céline, Guide, Camus, Yourcenar, Tournier y Quignard. Ayudado por ellos, fui encontrando mi voz en la escritura. Fue en París, por lo demás, donde dejé la interpretación de la música (durante más de diez años fui flautista) para dedicarme completamente a la literatura. Empecé, a su vez, mi carrera académica que es crucial en mi proceso intelectual y creativo. Ahora bien, el puente con lo social en Francia se estableció desde mi condición de asilado político colombiano. Recuerdo, por ejemplo, las lecturas de algunos de mis cuentos y poemas en eventos organizados por Amnistía Internacional, en numerosos eventos de cultura latinoamericana y mi participación en las marchas. Participé en muchas, desde las que protestaban por el genocidio de Ruanda y por la situación de los habitantes sin domicilio fijo, hasta las que rechazaban la xenofobia, las guerras de la OTAN y los proyectos contaminantes de energía nuclear. Fue en París, y desde París, donde publiqué mis primeros libros (Cuentos de Niquía, 1996; La sinfónica, 1997; Habitantes, 1999; Viajeros, 1999; y Razia, 2001). Y fue allí donde comprendí que debía ser un escritor comprometido con las luchas 
en cuyo centro está la defensa de la dignidad humana frente a los atropellos de los poderosos del mundo.

El tercer período inició cuando regresé a Medellín, en 2002, y culminó con la obtención del premio Rómulo Gallegos, en 2015. Me vinculé como profesor de literatura de la Universidad de Antioquia y, desde esta trinchera, he escrito la mayor parte de mis libros. En 2004 publiqué mi primera novela, La sed del ojo, que comienza una serie de obras que yo denomino de artista, porque sus personajes principales son fotógrafos, poetas, pintores, músicos que enfrentan desde sus oficios las sociedades turbulentas que les corresponden. Estas novelas son Lejos de Roma (2008), Los derrotados (2012), Tríptico de la infamia (2014), La escuela de música (2018) y La sombra de Orión (2021). Fue un período en que participé en muchos coloquios y congresos y publiqué una buena parte de mi obra ensayística, poética y cuentística. Incluso, desde mi puesto de profesor de literatura, he asumido una determinada proyección social. Todo este movimiento intelectual, de todas maneras, pasó en las coordenadas del mundo académico. A veces, recibía invitaciones para ir a ferias del libro o a festivales literarios. A la sazón era un escritor más o menos invisible, puesto que la mayoría de mis libros habían sido publicados por editoriales pequeñas y universitarias.

Pero esto terminó con la obtención del premio Rómulo Gallegos. Desde ese año, 2015, y hasta hoy, se ha configurado el que me parece es el cuarto período. Me volví un escritor "público". Mi nombre, mi figura, algunos de mis libros, aparecieron en los periódicos y los espacios culturales del país y América Latina. Ha sido un tiempo de numerosos viajes, de otros premios y condecoraciones y reconocimientos. He seguido escribiendo y publicando otros libros en medio de este intenso vértigo público. Y aunque sigo vinculado a pequeñas editoriales, Penguin Random House se ha encargado de editar una parte de mis libros. He aprovechado, por otro lado, esta visibilidad para manifestar mi descontento frente a la crisis climática. Desde Medellín he levantado una voz en defensa de los derechos de la naturaleza. Me he vuelto, como se dice, un intelectual comprometido con la defensa de la ecología. He manifestado, públicamente, mi rechazo al militarismo, a las fuerzas más reaccionarias de la política colombiana, a sus élites crueles y corruptas, y he criticado a las oposiciones armadas con las que, en algún momento de mi vida, tuve una cierta simpatía. He expresado con claridad mi posición de pacifista radical en medio de un país dominado por toda suerte de guerreros legales e ilegales. Quizás el momento culminante de esta posición la represente La sombra de Orión, en la que hago una radiografía del horror de la desaparición forzada en Colombia.

O.K.V.: Tus novelas se alimentan de diversos lenguajes de las artes: la pintura, la fotografía, el grabado, la música. Y, a su vez, cuando leemos tus novelas y cuentos constatamos que tu escritura entra también a nutrir esas manifestaciones estéticas que incorporas. No es posible leer Tríptico de la infamia sin remitirse a mirar, por caso, el cuadro de François Dubois La masacre de San Bartolomé, o en La escuela de música ensayar su lectura sin escuchar de Theodorakis el Canto General o el Réquiem de Berlioz. ¿Consideras que estas apuestas estéticas de vincular otros len- 
guajes artísticos llevan a nuevas expresiones, a una oxigenación, de la producción literaria colombiana?

P.M.: Mi formación académica me ha llevado a tener una idea más o menos completa de la literatura colombiana. Comprender, por ejemplo, cómo han evolucionado nuestras letras desde la colonia hasta nuestros días. Esto, sin duda, ha influido en mi escritura. De hecho, Pedro Cadavid expresa en varios momentos lo que significa escribir en un país como Colombia. En varios pasajes, en los libros donde es protagonista, se pregunta de qué manera se pueden oxigenar esas formas de narrar un proyecto nacional vapuleado por la violencia. Esa ha sido, pues, una de las formulaciones esenciales de mi obra. Plantearle al lector la dimensión de estas preguntas y mostrarle cómo se presenta una posible renovación. Desde mi época de Tunja, tuve consciencia de que una de las formas de escribir era apoyándome en lo artístico y así abordar la violencia, tanto la colombiana como la ecuménica, de un modo distinto. Mis dos primeros libros, Cuentos de Niquía (que son relatos más o menos oníricos con fondo de violencia), y La sinfónica (que son cuentos de artista dedicados a la música) marcan ese rumbo con la claridad de quien ya sabe para donde va. Y luego estos dos temas (el arte y la violencia) se irán imbricando de forma cada vez más compleja en las novelas de la madurez, como sucede en Los derrotados, Tríptico de la infamia y La sombra de Orión.

O.K.V.: En cuanto al lenguaje musical en tu escritura, recuerdo que la omnipresencia de la música en la existencia de los personajes que recorren tu novela La escuela de música, se insinúa desde el inicio con el epígrafe de Verlaine: "De la musique encore et toujours!". Y se sabe también de tu pasión literaria y musical por Carpentier y el papel decisivo que este ha jugado en tus apuestas estéticas. Mas, quizás, se conoce un poco menos de los escritores o artistas que han motivado tu interés por el lenguaje visual y su diálogo directo con la palabra literaria. ¿Hay acaso un escritor tan importante como Carpentier al momento de revisar la tradición literaria que nutre tu interés por el lenguaje visual?

P.M.: En varias ocasiones he señalado a Carpentier como el escritor que más me acompañó en el tránsito de la música a la literatura. Pero no fue el único. A su lado, hay autores de los que me he nutrido continuamente. Está el caso, por ejemplo, de Thomas Mann. Creo que una novela como La escuela de música le debe mucho más al alemán que al cubano. La mía es una novela de formación más emparentada a La montaña mágica que a Los pasos perdidos. La verdad es que pude resolver los problemas literarios que me planteó La escuela de música acudiendo al magisterio de Mann que, en cierta medida, es un descendiente del Goethe del Wilhelm Meister. Con lo visual hay varios autores que fui conociendo durante mi estancia en París. Está el caso de Baudelaire y de sus textos sobre pintura y fotografía. De hecho, La sed del ojo la escribí como un thriller erótico con un telón de fondo histórico donde las ideas de Baudelaire sobre la fotografía y la pintura son cruciales. La sed del ojo es una respuesta ficcional a los planteamientos con que este escritor repudió la llegada de este arte advenedizo y, según él, de segunda categoría al comparársele 
con la poesía y la pintura. En realidad, fueron los escritores franceses quienes me ayudaron a entender mejor la interesantísima relación existente entre literatura e imagen. Y ahí están las Piezas artísticas de Paul Valéry; las consideraciones de André Malraux en El museo imaginario; las maneras poéticas en que Élie Faure asume la historia del arte desde el paleolítico hasta la primera mitad del siglo xx; las aproximaciones literarias al mundo de la pintura de Proust, Yourcenar y Quignard; y las que hace Michel Tournier al de la fotografía. Todos ellos me fueron introduciendo a un universo apasionante donde la sensibilidad ante lo visual está apoyada siempre en una especie de erudición histórica y literaria. Pero no podría dejar pasar por alto, para situarnos en el terreno latinoamericano, la presencia de Octavio Paz. La lectura de sus ensayos y poemas dedicados a pintores y pinturas han sido para mí, desde que los conocí en mis años parisinos, como una carta de navegación.

O.K.V.: Con el personaje Pedro Cadavid, tu alter ego de escritor, se admite que hay en gran parte de tus novelas una "intromisión" in corpore e in verbis del autor en el mundo narrado, ¿Podríamos decir en tono "flaubertiano" que "Pedro Cadavid c'est moi"?, ${ }^{1}$ en el sentido que hay en la conciencia de Pablo Montoya tal presencia de su propio personaje que llega a sentir su tragedia o felicidad, las que él mismo ha creado.

P.M.: Durante un tiempo sentí una suerte de pudor de entrometer mi vida directamente en los libros que iba escribiendo. Por tal razón, decidí ocultarme, o disfrazarme, o mimetizarme. Podría decir que, en Viajeros, Trazos (2007) y Programa de mano (2014), me escondo detrás de los personajes de la historia y la imaginación que propongo a través de estas prosas poéticas. Pero en algunos cuentos de Réquiem por un fantasma (2006) empieza a configurarse la presencia de un personaje que, más tarde, será el Pedro Cadavid de las novelas. En Los derrotados es evidente la apuesta metaficcional que tiene como autor principal a este alter ego mío. Es como si al abordar la novela, que para mí ha sido el género de la madurez literaria, se me hubiera dado el permiso de construir un personaje que, a su vez, me ha posibilitado expresarme como persona, artista, intelectual y ciudadano. Por eso el personaje que articula mis libros sobre la violencia en Medellín es Pedro Cadavid. La fórmula flaubertiana me parece plausible en el vínculo entre ambas instancias, una real y otra ficcional. Sobre todo, cuando Cadavid se asume como un escritor que no solo escribe literatura, sino que se pregunta constantemente cómo escribirla. En esto reside el puente con Flaubert, un autor al que he leído y releído hasta llegar a traducir sus Tres cuentos al español. Flaubert es, por lo demás, el escritor que asume la aventura de la escritura como un paraíso y un infierno, como salvación y condena. Esta lucha con la palabra justa, con la búsqueda de un estilo literario que pretende rozar la perfección, son asuntos que me conciernen demasiado. O sea que Flaubert podría servir como un espejo en que parte de mi labor escritural se refleja.

\footnotetext{
1 Si bien se discute hoy la autoría de la frase "Madame Bovary, c'est moi", expresada por Flaubert, esta proposición sigue intacta en su sentido porque conserva aún la idea del "personaje vivo" como efecto de la tensión entre la sensibilidad del autor y el acto mismo de su escritura.
} 
O.K.V.: En relación con la pregunta anterior y aceptando que la identidad nominal está íntimamente ligada al ser que señala y contiene por ello una buena dosis simbólica y afectiva, he rastreado en tu narrativa el sentido del nombre de tu personaje y encontré, quizás, un indicio en el cuento "Las formas del silencio", en que el narrador, un escritor que ha abandonado el mundo de la música y la vida sonora, se identifica con el San Pedro apóstol de una crónica cristiana apócrifa. Como este, el narrador-escritor se siente taciturno y proclive a la soledad. Comparten el deseo del silencio absoluto como estado de reconciliación consigo mismo y acceso a la "verdad" y la plenitud del amor. ¿Hay alguna relación entre Pedro Cadavid y el San Pedro apócrifo, o de dónde surge el nombre Pedro Cadavid?

P.M.: Cuando era adolescente, y empezó a manifestarse mi rebeldía en el seno de una familia muy conservadora antioqueña, no me gustaba mucho mi nombre. Pablo significa pequeño, persona humilde. Eso me gustaba, por supuesto. Pero la alusión al personaje apóstol no me llamaba mucho la atención. San Pablo para mí ha sido uno de los personajes más polémicos de la Antigüedad. Su publicidad del cristianismo me produce escozor y sus cartas, la verdad sea dicha, no me atraen demasiado. Pedro y su alusión a la piedra, como solidez y resistencia, en cambio, me llamó poderosamente la atención por aquellos años. Tal vez esta fascinación por este nombre griego y posteriormente latinizado y españolizado haya influido en esta mi literaria. El Cadavid, por su parte, es uno de mis apellidos familiares, muy arraigado, como el Montoya y el Campuzano, en Antioquia. Ahora bien, la alusión a San Pedro en el cuento "Las formas del silencio" tiene que ver con una lectura que hice de los ensayos de Pascal Quignard, El odio a la música, otro autor al que he traducido varias veces. Allí hay un ensayo sobre la relación anómala entre San Pedro y los sonidos que me pareció pertinente citar a propósito de esa fobia sonora que padece el personaje de mi cuento. Personaje que trato con cierta amplitud en La sombra de Orión, ya que el protagonista de "Las formas del silencio" es el músico que en la novela registra los rastros sonoros de los desaparecidos de la escombrera.

O.K.V.: El interés por los muertos inermes y la política criminal de la muerte son un motivo de recurrente preocupación por todos tus personajes artistas: escritor, músico, pintor, fotógrafo. Incluso, en La sombra de Orión, Pedro Cadavid se pregunta por la tradición estética de los novelistas colombianos en la figuración de la violencia a partir del cuestionamiento de García Márquez sobre las formas literarias que venían alimentado una "literatura de urgencia" y la fijación literaria en un punto ajeno a lo explícito de los muertos. ¿Cuál sería para ti el giro moral que ha dado hoy la reflexión sobre la violencia política en el discurso literario, cuando, justamente, el cuerpo deshecho, los muertos y los desaparecidos empiezan a ocupar el primer plano en una parte de las propuestas de escritura colombiana?

P.M.: García Márquez renovó la literatura de la violencia en Colombia. Fue una labor que hizo en compañía de Cepeda Samudio, Mejía Vallejo, Hernando Téllez y Eduardo Caballero Calderón, entre otros. La postura de García Márquez consistió 
en escribir una literatura donde lo explícito de la violencia es rechazado. Yo he tomado, de algún modo, un camino diferente. Me apoyo, y en esto estoy de acuerdo con el Nobel, en la necesidad de demostrar oficio, manejo de técnicas narrativas, dominio de un estilo literario en lo que se escribe. García Márquez, a propósito, decía que el gran problema de la literatura de la violencia partidista era la falta de oficio que manifestaban los escritores de entonces. Desde los personajes artistas de mis libros, y distante a la propuesta de García Márquez, yo he elaborado una serie de catálogos del horror. Ahí está el catálogo de las masacres descrito desde una serie de fotografías en Los derrotados. El catálogo del exterminio indígena hecho desde la interpretación de una serie de grabados en Tríptico de la infamia. Y el catálogo de desaparecidos presentado en La sombra de Orión donde poesía y periodismo confluyen. ¿Por qué hacerlo? Una explicación apuntaría, al menos en mi caso, al hecho de que la violencia colombiana se ha desbordado de tal forma que sería difícil desconocer su ubicuidad tenebrosa. Como dejar pasar por alto, en la literatura, que somos un país donde hay más de cien mil desaparecidos, con una guerra permanente que ha dejado cientos de miles de asesinados, con exterminios políticos que no cesan, con miles de falsos positivos, con más de seis millones de desplazados internos y otros tantos que están en el exilio. Estas cifras demuestran el rotundo fracaso del proyecto nacional llamado Colombia. Es verdad que la novela es, entre otras cosas, una recreación poética de la realidad, como decía García Márquez. Pero también es cierto que nuestra realidad está moldeada por la violencia. Pero otra posible explicación sería la de introducir, en estos catálogos de muertes, una necesaria dosis de ética. Este giro moral al que te refieres me parece esencial. De hecho, uno de los problemas que me suscita una buena parte de la literatura de la violencia colombiana es su poco espesor moral. Algo que termina convirtiéndola en algo banal, espectacular y amarillista.

O.K.V.: Se reconoce que los estudios sobre la novela colombiana que tematiza la violencia se han apoyado, sobre todo, en conceptos de las ciencias sociales y del discurso histórico, remarcando en las causas políticas y sociales del conflicto. $Y$ cuando se reflexiona sobre los efectos psicosociales se enfocan habitualmente los elementos activos que los desencadenan -sicarios, narcotraficantes, personajes de perfil político, narradores militantes, etc.-. Las metáforas del poder juegan de este modo el rol central en gran parte de la crítica literaria. Tú como estudioso de la literatura colombiana ¿qué mirada tienes sobre las formas como la violencia atroz se ha figurado en las letras colombianas?

P.M.: Se nos dijo, durante un tiempo, que el gran conocedor de las dinámicas del poder en Colombia era García Márquez. Y nos mostraban, por ejemplo, los militares de su obra que, generalmente, son vencidos. Aureliano Buendía, el coronel al que nadie le escribe son dos personajes que hicieron la guerra de los Mil días, pero terminan siendo vencidos. También nos dijeron que el mayor exponente de ese tipo de poder militar era el dictador de El otoño del patriarca. Lo que me ha preocupado a mí, al respecto, son los vencidos civiles y no los guerreros. Y para hacerlo, repito, me he apoyado en un tipo de víctimas. De hecho, el patriarca de 
García Márquez siempre me ha parecido un personaje repudiable, no solo porque es un victimario, sino porque carece de espesor moral y ético. En el fondo de ese delirio verbal, que ha subyugado a tantos y con el cual se construye la novela, se agita un espécimen repugnante. $Y$ es que si pasamos revista a una buena parte de la literatura de la violencia en Colombia se constata que lo que prevalecen son asesinos, sicarios, mafiosos, personas, en fin, que carecen de cualquier catadura humana. $\mathrm{O}$, si la poseen, esta se oculta detrás de psicologías y anatomías hechas para matar o provocar el mal. La narcoliteratura, la paraliteratura, la sicaresca han caído de hinojos ante estas figuras aciagas. Cuando estaba escribiendo los cuentos de Réquiem por un fantasma me di cuenta de que debía ocuparme del otro lado del fenómeno, es decir, de las víctimas. Y creo que este rumbo lo continúa La sombra de Orión. Mírese, por ejemplo, el catálogo de desaparecidos llamado "La escombrera". Lo conforman veintiséis semblanzas cuyos protagonistas son casi anónimos. Todos ellos de origen popular, gente pobre y humilde, personas buenas, pero que han sido embestidas por el flagelo de la desaparición forzada. Considero, en esta perspectiva, que la metáfora de los vencidos colombianos de ahora la conforman los miles de desaparecidos que ha provocado la dinámica política de este país.

O.K.V.: Y, frente a las metáforas de los vencidos colombianos ¿cuál consideras que es el papel de la crítica literaria?

P.M.: Hablar de crítica literaria es referirse a historias de la literatura, a aspectos polémicos como el canon y la recepción y difusión de los libros y sus autores. Es sopesar, además, esa movilidad cultural en que aparecen los dueños del poder económico, político y religioso para intervenir en los asuntos de la valoración literaria. En este sentido, desde la Antigüedad hasta nuestros días, la literatura se ha valorado, o criticado, desde esas orillas. Esto no significa, por supuesto, que la literatura asociada al poder de los vencedores sea negativa. Solo basta mirar el caso de la Eneida. Virgilio la escribió para el beneplácito de Augusto, pero quiso destruirla, antes de morir, porque le pareció imperfecta y quizás cuestionable hacer un libro para enaltecer el poder militar de Roma. Pero terminó escribiendo una de las obras más esenciales, y más impresionantes justamente por su altura estética, de la cultura occidental. Sin embargo, en el fondo lo que se nos cuenta en la Eneida está lleno de sufrimientos y pareciera que se estuviera cantando una serie de derrotas humanas. Lo mismo sucede con Homero. Leemos la llíada y nos sentimos atraídos por los troyanos, que son los vencidos en la larga guerra. Si hay un pasaje que nos entristece es la muerte de Héctor. Y lloramos esperanzados cuando, por fin, el anciano Príamo puede rescatar el cadáver de su hijo de las manos de un Aquiles estremecido por la rabia y la desolación. Lo que quiero decir es que muchos de los grandes libros de la literatura son narraciones o cantos del fracaso, de la crisis y la conflagración de los hombres. Y son esos libros, extraña paradoja, los celebrados por los vencedores. Incluso, se podría afirmar que una buena parte de la crítica literaria, al oficializarse, se vuelve una suerte de instrumento hermenéutico del poder. Ahora bien, si esto ha sucedido durante siglos, lo que está 
presentándose en la actualidad, con la crisis de las democracias neoliberales y el cambio climático, las pandemias, los grandes movimientos de protesta planetaria y las nuevas y transgresoras epistemologías de la cultura, es muy sugestivo. Se está poniendo en tela de juicio, desde la antropología, la filosofía, la sociología, la historia y el arte, ese poder que nos tiene como nos tiene, en tanto que civilización y especie. Un poder, es casi una perogrullada decirlo, que ha estado vinculado al sistema patriarcal, que es masculino, misógino, militar y monoteísta en buena parte. $Y$ esto es evidente cuando observamos el caso de la literatura colombiana y su valoración. Las primeras historias de nuestra literatura, por ejemplo, fueron escritas por hombres defensores de las grandes instituciones oficiales de la nación tales como la Iglesia católica, los dos partidos políticos tradicionales y las fuerzas militares del Estado. Todas estas historias surgieron, por lo demás, en uno de los períodos más reaccionarios que como país hemos tenido, el de las últimas décadas del siglo xIx e inicios del xx. La crítica literaria en Colombia nació y se ha desarrollado en estos contextos ideológicos. Lo cual nos permitiría decir que son valoraciones de obras de los vencedores o, en algunos casos, de los vencidos pero que han sido asimiladas por el poder vencedor. De hecho, me atrevería a pensar que el fenómeno de la recepción por parte de la crítica de las novelas de la violencia en Colombia, donde es claro ver la oposición entre vencedor y vencido, entraría en estas coordenadas. Son novelas que narran traumas de derrotados pero que atraen al poder victorioso y este apuesta por su canonización. Sin embargo, ahora estamos presenciando grandes mutaciones sociales que la crítica literaria asimilará de un modo u otro. Vendrán nuevas lecturas interpretativas de esas obras literarias que han sido enaltecidas por ese poder mencionado (el periodístico, el editorial comercial, el político y hasta el académico), y que, quién sabe, si lo seguirán siendo en el futuro. El panorama entonces está, por fortuna, transformándose, y aparecerán metáforas más eficaces y esclarecedoras de los vencidos.

O.K.V.: Y para acabar, has comentado que con la reciente publicación de La sombra de Orión cierras el ciclo de escritura sobre la violencia colombiana. Por tanto, ¿cuáles son en este momento tus proyectos literarios cercanos?, ¿qué otros intereses creativos podrían motivar más adelante nuevas novelas o cuentos?

P.M.: La verdad es que, además de cerrar este ciclo, que inició con mi primer libro, Cuentos de Niquía, con la escritura de La sombra de Orión he quedado extenuado. No sé muy bien si es un cansancio ocasionado por la envergadura de la empresa acometida, o si se trata de un agotamiento generado por el mismo tema de la desaparición. Cuando lo abordé, fui consciente de que pisaba terrenos donde casi todo es frustración, desolación, oscuridad, resentimiento, impotencia, maldad. Sé que he llegado, en todo caso, a una especie de punto final. La sombra de Orión es la culminación de un proceso. En sus páginas confluyen temáticas, personajes, pesquisas estilísticas y literarias que he trabajado en otros libros. Por tal razón, lo que sigue apuntará a otros mundos y a otras épocas. Siento, por ejemplo, una profunda atracción por el pasado. Ese pasado se llama la Roma antigua, a la que tanto debe Lejos de Roma y Hombre en ruinas (2018). También es el Renacimiento 
flamenco, que nutre una buena parte de Tríptico de la infamia. Asimismo, está el pasado colombiano, que moldea Los derrotados y Adiós a los próceres (2010). Y en medio de esas épocas se ha levantado siempre la figura del artista, del pensador, del personaje libertario que tanto me han atraído. Creo que mi próxima narrativa volverá sobre esos tópicos y esos tiempos. Pero está, igualmente, la escritura ensayística. Por lo pronto, y al terminar La sombra de Orión, me he sumergido en una serie de crónicas ensayos que tratan sobre escritores que para mí han sido fundamentales. Hago el viaje a uno de los sitios emblemáticos del escritor seleccionado (una casa natal, algún museo, una tumba), y a partir de esta experiencia escribo lo que podría ser un relato de viaje. Pero, a la vez, hago un balance general de esa obra que me ha enseñado a mirar el mundo, a comprender la condición humana, a gozar de la literatura como si ella fuera lo más importante que a mí, como ser humano, me ha sucedido. Pronto tendré sesenta años y es hora, pienso, de hacer estos balances personales. Por este motivo, este proyecto, que he titulado Peregrinaciones literarias, no es más que un gesto de gratitud a la tradición literaria. Sin ella, sin esos autores admirados, amados, criticados, lo mío sería poca cosa en esta maravillosa aventura de la escritura. 